\title{
Labor Epidural in a Patient Who is Allergic to Lidocaine: A Case Series
}

This article was published in the following Dove Press journal:

Local and Regional Anesthesia

\author{
Akshatha Kamath \\ Vikas Raghove (D) \\ Allison Kalstein \\ Joel Yarmush
}

Department of Anesthesiology, NYP Brooklyn Methodist Hospital, Brooklyn, NY, USA
Correspondence: Vikas Raghove Department of Anesthesia, NYP Brooklyn Methodist Hospital, $5066^{\text {th }}$ Street,

Brooklyn, NY, II 1215 , USA

Tel +l 6462406269

Email vikasraghove@gmail.com

\begin{abstract}
Continuous epidural anesthesia is considered the best modality for pain relief during labor, local anesthetic allergy is an uncommon occurrence but if a patient has an allergy to bupivacaine or lidocaine owing to its cross-reactivity with bupivacaine then it becomes very challenging to manage labor analgesia. A direct challenge test to rule out actual hypersensitivity was not considered a viable option given the risks involved if a severe allergic reaction occurred with the test dose. Using IV opioid-based analgesia has harmful effects for both mother and the baby in addition to decreasing participation of mothers in the birthing process owing to its sedative properties. We report two cases where the mother had a history of lidocaine allergy, so labor analgesia was managed using chloroprocaine patientcontrolled epidural analgesia (PCEA).
\end{abstract}

Keywords: lidocaine allergy, labor analgesia, chloroprocaine epidural, local anesthetic allergy, chloroprocaine patient-controlled epidural analgesia

\section{Introduction}

Local anesthetics are very commonly used drugs. Lidocaine after being first manufactured in 1943 is still extensively used with a good safety record if given in prescribed dose. Hypersensitivity reaction to local anesthetics are rare and many adverse reactions are mislabeled as an allergic reaction. ${ }^{3}$ Local anesthetics are primarily of two types amino amides and amino esters. Both lidocaine and bupivacaine are amino amides and share some cross-reactivity concerning allergic reactions. ${ }^{3}$ Our patients had an allergic reaction to the amino amide class of local anesthetic namely lidocaine, so we decided to use an amino ester local anesthetic chloroprocaine instead. The use of chloroprocaine in PCEA is not a widely accepted practice and is mostly documented in case reports or small series. Mention of chloroprocaine safe usage in literature may prompt its wider usage.

\section{Case I}

A 25-year-old G2P1 parturient with no major co-morbidity except for the history of lidocaine allergy in childhood presented to our hospital with 37 weeks' gestation in an active phase of labor. She did not remember the exact details of allergic reaction as it "occurred in childhood". Her airway exam was reassuring. Though direct challenge can be tried with non-proven local anesthetic allergy, ${ }^{4}$ or skin testing, it was not planned considering the risk for the mother and the baby in case of anaphylaxis. We discussed at length the possible pain relief modalities including the risk and benefits of chloroprocaine PCEA and remifentanil intravenous (IV) 
patient-controlled analgesia (PCA). The patient opted for chloroprocaine PCEA after understanding the risks and the benefits. Standard ASA monitors were applied, an $18 \mathrm{G} \mathrm{IV}$ was placed, and the patient was prepared for the procedure with the code cart in the labor room. The obstetric team was made aware to be on standby if anaphylaxis occurred and stat delivery of the fetus was necessary. We performed skin testing with $0.1 \mathrm{~mL}$ of chloroprocaine subcutaneously, followed by $0.5 \mathrm{~mL}$ and $1 \mathrm{~mL}$ of the same, no allergic reactions were noted, and the vital signs were stable $2 \mathrm{~mL}$ of chloroprocaine $1.5 \%$ (Nescaine MPF) was used to numb the skin. The epidural catheter placement was performed easily, and $8 \mathrm{~mL}$ of chloroprocaine $1.5 \%$ was used as a loading dose. A pump for patient-controlled epidural analgesia (PCEA) at a basal rate of $12 \mathrm{~mL} / \mathrm{hr}$ of chloroprocaine $1.5 \%+$ fentanyl $2 \mathrm{mcg} / \mathrm{mL}$ with optional boluses of $5 \mathrm{~mL}$ every 20 minutes was started. She was closely monitored for any symptoms of allergic reactions. She was comfortable, with no symptoms of allergic reactions, and had a spontaneous vaginal delivery, after eight hours without issues. Mother and baby were discharged home on the third postpartum day. Our patient was advised to visit an allergist six months post-delivery.

\section{Case 2}

A 36-year-old G2P1 parturient with a history of gastroesophageal reflux disease with the fetus in a cephalic presentation in an active phase of labor requested labor analgesia. She reported a history of swelling of the throat on lidocaine gargle years prior. She had reassuring airway, cardiac, liver, lung, and kidney functions. The patient decided to proceed with the epidural analgesia using chloroprocaine for pain relief, after discussing the options available. The code cart was kept in the room, and the obstetric team was made aware. The epidural catheter placement was done and a pump for patient-controlled epidural analgesia (PCEA) at a basal rate of $12 \mathrm{~mL} / \mathrm{hr}$ of chloroprocaine $1.5 \%+$ fentanyl $2 \mathrm{mcg} / \mathrm{mL}$ with optional boluses of $5 \mathrm{~mL}$ every 20 minutes was started. However, the patient reported severe back spasm, which she described as burning pain deep in the muscles and was not willing for the continuation of epidural boluses of chloroprocaine. After a total of $30 \mathrm{~mL}$ was infused PCEA was discontinued. After an hour, the Ob team treated her with intermittent doses of Stadol (nalbuphine). The patient was comfortable with the intermittent boluses of nalbuphine, and she delivered a healthy baby after ten hours.

\section{Discussion}

Epidural anesthesia is considered the best modality for labor analgesia. ${ }^{1,2}$ With intravenous opioid-based analgesia marred with lesser pain relief and a higher rate of adverse effects. ${ }^{4-7}$ True allergy to local anesthetic is not common. ${ }^{8}$ Allergic reaction is commonly triggered by preservative methylparaben, para-aminobenzoic acid which is a metabolite of the amide group of local anesthetics, or ester or amide component. ${ }^{9-11}$

If allergy to local anesthetic is reported it is very important to evaluate it further pre-conception or early in pregnancy. First is a careful history as symptoms like palpitations, vasovagal attacks, and anxiety during the IV injections can be mistaken for allergic reactions by the patient. $^{8}$ A detailed history should be elicited for true allergic reactions like rashes, bronchospasm, urticarial, angioedema, and cardiovascular collapse. ${ }^{8}$ If allergy to lidocaine is true, bupivacaine cannot be used as it is also an amide group local anesthetic and has cross-reactivity with lidocaine ${ }^{2}$ though the exact rate is not known. Skin testing or challenge dose of local anesthetic can be used ${ }^{4}$ and would have been ideal if this patient was reviewed pre-conception or in the second trimester.

Chloroprocaine is a fast-acting local anesthetic with a short duration of action and belongs to the ester group with no cross-reactivity to lidocaine which is an amide. It is rapidly hydrolyzed by plasma esterases. Chloroprocaine is very rarely used in labor epidural anesthesia possibly due to the possibility of cauda equina syndrome and arachnoiditis with unintentional intrathecal administration. ${ }^{12}$ Now the preservative-free chloroprocaine is being used as a spinal anesthetic without complications. ${ }^{13}$

The dosing of chloroprocaine has not been standardized yet and we used the dose used by Lee ${ }^{14}$ though lower dosing has been recommended by Coffman et al. ${ }^{15}$ As a conclusion, we would say that local anesthetic allergy is reported it should be evaluated early and in pregnancy and chloroprocaine, epidural analgesia is an underutilized modality of pain relief. We would also agree with Coffman et al to decrease the dosing needed to further increase the safety profile and think that it should be further evaluated to standardize the dosing regimen. The downside of the chloroprocaine is the back muscle spasms as in our case 2 and the unintended motor blockade which could be uncomfortable for the patient. Muscle spasms are more common with chloroprocaine containing EDTA as a preservative with doses of more than $40 \mathrm{~mL}$. In our 
patient, a total of $30 \mathrm{~mL}$ was used before it was discontinued.

\section{Conclusion}

Appropriate alternative medications can be used only if we understand the basic pharmacology of the medications. It is crucial to elicit a detailed history regarding the allergic reaction as we can rule out the side effects of the medications which could be misinterpreted as an allergic reaction by the patients. Clinicians should be aware of the necessity of the proper evaluation of the patients who report a local anesthetic allergy to an allergist and an anesthesiologist early in pregnancy.

\section{Consent Statement}

Both the patient's informed consent was obtained for the publication of the report. Study was approved for publication by New York-Presbyterian Brooklyn Methodist Hospital institutional review committee.

\section{Acknowledgment}

We appreciate the input of Dr. Minal Joshi.

\section{Disclosure}

None of the authors have any conflicts of interest to disclose.

\section{References}

1. Bonnet MP, Prunet C, Baillard C, et al. Anesthetic and obstetrical factors associated with the effectiveness of epidural analgesia for labor pain relief: an observational population-based study. Reg Anesth Pain Med. 2017;42(1):109. doi:10.1097/AAP.0000000000000517

2. Eltzschig HK, Lieberman ES, Camann WR. Regional anesthesia and analgesia for labor and delivery. $N$ Engl J Med. 2003;348(4):319. doi:10.1056/NEJMra021276

Local and Regional Anesthesia

\section{Publish your work in this journal}

Local and Regional Anesthesia is an international, peer-reviewed, open access journal publishing on the development, pharmacology, delivery and targeting and clinical use of local and regional anesthetics and analgesics. The journal welcomes submitted papers covering original research, basic science, clinical studies, reviews \&
3. Thyssen JP, Menne T, Elberling J, et al. Hypersensitivity to local anesthetics-update and proposal of evaluation algorithm. Contact Dermatitis. 2008;59(2):69. doi:10.1111/j.1600-0536.2008.01366.x

4. Barer MR, McAllen MK. Hypersensitivity to local anaesthetics. $\mathrm{Br}$ Med J. 1982;284:1229.

5. Kan RE, Hughes SC, Rosen MA, et al. Intravenous remifentanil: placental transfer, maternal and neonatal effects. Anesthesiology. 1998;88(6):1467-1474. doi:10.1097/00000542-199806000-00008

6. Tveit TO, Seiler S, Halvorsen A, et al. A randomized, controlled trial comparing intravenous remifentanil and epidural analgesia with ropivacaine and fentanyl. Eur $J$ Anaesthesiol. 2012;29(3):129-136. doi:10.1097/EJA.0b013e32834dfa98

7. Logtenberg S, Oude Rengerink K, Verhoeven CJ, et al. Labour pain with remifentanil patient-controlled analgesia versus epidural analgesia: a randomized equivalence trial. BJOG. 2017;124(4):652-660. doi:10.1111/1471-0528.14181

8. Bhole MV, Manson AL, Seneviratne SL, et al. IgE mediated allergy to local anaesthetics: separating fact from perception: a UK perspective. BJA. 2012;108(6):903-911. doi:10.1093/bja/aes162

9. Ring J, Franz R, Brockow K. Anaphylactic reactions to local anesthetics. Chem Immunol Allergy. 2010;95:190-200.

10. Cuesta-Herranz J, de Las Heras M, Fernández M, et al. Allergic reaction caused by local anesthetic agents belonging to the amide group. J Allergy Clin Immunol. 1997;99(3):427-428

11. Eggleston ST, Lush LW. Understanding allergic reactions to local anesthetics. Ann Pharmacother. 2018;30(7-8):851-857. doi:10.1177/ 106002809603000724.

12. Reisner LS, Hochman BN, Plumer MH. Persistent neurologic deficit and adhesive arachnoiditis following intrathecal 2-chloroprocaine injection. Anesth Analg. 1980;59(6):452-454. doi:10.1213/ 00000539-198006000-00014

13. Bhaskara B, Prabhakar SA, Rangadhamaiah R. Intrathecal 1\% 2-chloroprocaine with fentanyl in comparison with ropivacaine $(0.5 \%)$ with fentanyl in day care perianal surgery: prospective randomized comparative study. Anesth. 2019;13(3):471.

14. Lee SC, Moll V. Continuous epidural analgesia using an ester-linked local anesthetic agent, 2-chloroprocaine, during labor: a case report a\&a case reports. A \& a Case Reports. 2017;8(11):297-299. doi:10.1213/XAA.0000000000000494

15. Coffman JC, Brower KI, Small RH. Is low concentration 2-chloroprocaine for epidural labor analgesia a better option? $A$ a Pract. 2018;10(4):95. doi:10.1213/XAA.0000000000000634

\section{Dovepress}

evaluations, guidelines, expert opinion and commentary, case reports and extended reports. The manuscript management system is completely online and includes a very quick and fair peer-review system, which is all easy to use. Visit http://www.dovepress.com/testimonials. php to read real quotes from published authors. 